\title{
PECULIARIDADES DA 'METADE SUL' GAÚCHA E SUAS IMPLICAÇÕES PARA A GEOCONSERVAÇÃO, O GEOTURISMO E OS GEOPARQUES
}

\author{
André Weissheimer de Borba, Adriano Severo Figueiró, Taís da Silva Garcia, \\ Silvio Ávila Domingues, Luiz Paulo Martins e Souza
}

Universidade Federal de Santa Maria, Centro de Ciências Naturais e Exatas, Departamento de Geociências (DEP-GEO/CCNE/UFSM), Av. Roraima, 1000, prédio 17, sl. 1131B, CEP 97.105-900, Camobi, Santa Maria/RS. awborba.geo@gmail.com

RESUMO: A 'metade sul' gaúcha possui um patrimônio geológico singular: (a) lagoas, praias e dunas do litoral; (b) paisagens graníticas das serras do Herval e Canguçu, raízes de antiga cadeia montanhosa; (c) Caçapava do Sul, incomparável sala de aula ao ar livre para o ensino de geociências; (d) cerros tabulares e areais que testemunham a superposição de desertos; e (e) o Cerro do Jarau, cratera de meteoro e cenário de lendas gaúchas. Por outro lado, a região apresenta deficiências profundas na educação, sua infraestrutura turística é precária, e seus atributos naturais estão desprotegidos e vulneráveis frente a empreendimentos danosos. As geociências, nessa nova tendência de busca da sustentabilidade e retorno socioambiental, precisam divulgar a importância e a necessidade de proteção desse geopatrimônio insubstituível. Para que, no futuro, se possa pensar em 'geoparques', os geocientistas devem imediatamente focalizar ações efetivas de geoconservação na região: (1) apontar geossítios importantes, a serem protegidos por UC, figuras legais imprescindíveis à qualidade ambiental da região; (2) qualificar professores da educação básica em tópicos de geociências, estimulando o uso de exemplos locais em suas aulas; e (3) participar na montagem de roteiros geoturísticos interessantes, recheados de cultura e conhecimento.

Palavras-chave: patrimônio geológico, geoconservação, 'metade sul', Rio Grande do Sul.

ABSTRACT: CHARACTERISTICS OF THE 'SOUTHERN HALF' OF THE RIO GRANDE DO SUL STATE AND ITS IMPLICATIONS FOR GEOCONSERVATION, GEOTOURISM, AND GEOPARKS. The so-called 'southern half' of the Rio Grande do Sul State possesses a singular geological heritage: (a) beaches, lagoons, and dune fields at the coast; (b) granitic landscapes of Herval and Canguçu, roots of an ancient mountain range; (c) the Caçapava do Sul region, unmatched open-air classroom for geosciences teaching; (d) table hills and sand fields that record the superposition of deserts; and (e) the Jarau hill, meteor crater and scenario of traditional gaucho tales. On the other hand, the region displays profound deficiencies in basic education, weak tourist structure, and nature monuments threatened by potentially damaging enterprises. Geosciences, in the current trend of seeking sustainability and social-environmental feedback, must divulge the importance and the protection need of this irreplaceable geoheritage. In order to consider, in the future, eventual bids for the 'geopark' certification, geoscientists should immediately focus on effective geoconservation initiatives for the region: (1) recommending geosites suitable for legal protection; (2) qualifying basic education teachers in geology-related topics, stimulating the use of local examples in the classes; and (3) participating in the design of interesting, knowledge-based tourist programs.

Keywords: geological heritage, geoconservation, 'southern half', Rio Grande do Sul State.

\section{INTRODUÇÃO}

A 'metade sul' do Estado do Rio Grande do Sul, ao sul do paralelo $30^{\circ} \mathrm{S}$, é a região geologicamente mais antiga, mais complexa, mais diversificada e mais interessante em termos estaduais, possuindo rochas e depósitos do Arqueano ao Quaternário. Seus ecossistemas incluem florestas, campos nativos, savanas e areais: a atual conformação do pampa gaúcho. Nesse ambiente nasceu e se desenvolveu a própria cultura gaúcha: da pecuária extensiva, das cavalgadas, do churrasco, do chimarrão, das grandes distâncias, da solidão. Os 'rigores do pampa', hoje, se refletem em números alarmantes nos indicadores de desenvolvimento humano e socioeconômico: educação deficitária, baixa escolaridade, infraestrutura precária e condições de vida muito abaixo da média estadual. Esse contraste deve ser o foco de estratégias e iniciativas de geoconservação. É papel dos geocientistas analisar as características da 'metade sul' em termos de seu patrimônio geológico, do potencial e das eventuais dificuldades a serem encontradas para sua proteção, valorização e utilização sustentável como motor de desenvolvimento. Aqui, apresentam-se algumas dessas características e, também, as implicações que elas trazem à aplicação da geoconservação. Esperase que esta reflexão seja considerada em futuras estratégias, de modo que se possa influenciar positivamente na tentativa de buscar um equilíbrio entre desenvolvimento, natureza e sociedade na região mais pobre do Rio Grande do Sul.

\section{O PATRIMÔNIO GEOLÓGICO DA 'METADE SUL' GAÚCHA}

A 'metade sul' do Rio Grande do Sul é a porção mais geodiversificada do Estado. Imaginando-se uma linha reta, de direção ESE-WNW, do litoral junto ao Oceano Atlântico até as 'barrancas' do Rio Uruguai (Fig. 1), cruzam-se inúmeros tipos de rochas, depósitos, formas de relevo e paisagens. É a porção do Rio Grande do Sul que conta com os mais coloridos mapas geológicos e geomorfológicos, recortados por estruturas tectônicas NE e banhados por dois grandes rios: o Camaquã, que corre para leste e drena para a Laguna dos Patos; e o Ibicuí, que carrega suas águas e sedimentos no sentido oeste, em direção ao rio Uruguai e à Bacia do Prata. 


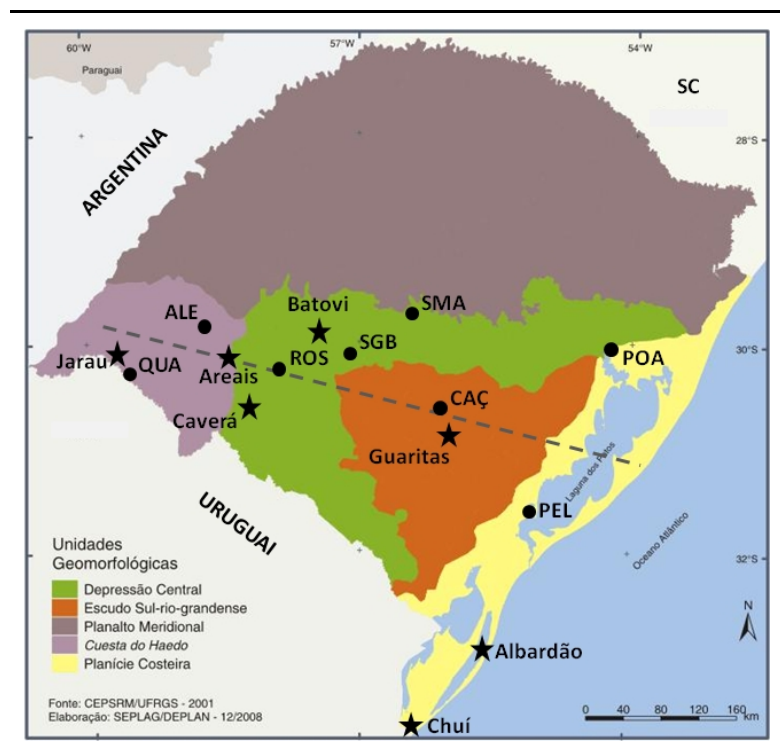

Figura 1 - Mapa de unidades geomorfológicas do Rio Grande do Sul, divulgado pela UFRGS em 2001, com inserção das cidades citadas no texto e dos geossítios ou destaques geopatrimoniais da 'metade sul' gaúcha; estão plotadas (círculos negros) no mapa as cidades de Porto Alegre (POA), Pelotas (PEL), Caçapava do Sul (CAÇ), Santa Maria (SMA), São Gabriel (SGB), Rosário do Sul

(ROS), Alegrete (ALE) e Quaraí (QUA); as estrelas negras representam os geossítios citados: Albardão, barrancas do Chuí, Guaritas de Caçapava, serra do Caverá e coxilhas do tipo Batovi, os areais da campanha e, no extremo oeste, o Cerro do Jarau; a linha pontilhada cinza-clara representa um perfil imaginário de ESSE a WNW, conforme citado acima, no texto.

A faixa litorânea corresponde à porção sul da Planície Costeira, formada por sucessivos sistemas laguna-barreira desenvolvidos nos últimos $400 \mathrm{mil}$ anos. Dominada pela Laguna dos Patos, que recebe sazonalmente as águas do mar, a paisagem conta ainda com praias retilíneas, lagoas fechadas e muito rasas (Mirim, Mangueira e do Peixe), paraísos para aves migratórias de norte e de sul, além de extensos campos de dunas, como as Dunas do Albardão, geossítio inscrito na lista SIGEP (Lopes et al., 2008). Também fazem parte deste contexto as "barrancas fossilíferas do arroio Chuí" (Lopes et al., 2005), outro integrante da lista do patrimônio geológico brasileiro, depósitos fluviais costeiros onde se acumularam restos fósseis de preguiças-gigantes, equídeos e outros componentes da megafauna pleistocênica, hoje extinta.

Imediatamente a oeste, localiza-se o Escudo Sulrio-grandense, correspondente ao Planalto Sul-riograndense ou Serras de Sudeste, uma área relativamente alta (até 500 metros de altitude), de relevo acidentado. Ali, afloram as rochas mais antigas do Estado, desde o Arqueano até o limite Neoproterozoico/Paleozoico inferior (Chemale Jr., 2000). As paisagens graníticas das serras do Herval (Fig. 2A) e de Canguçu, com seus campos de matacões arredondados, são registros das raízes de uma antiga e extensa cadeia montanhosa, que se estendia do Uruguai a Santa Catarina. A região também abriga Caçapava do Sul, 'capital gaúcha da geodiversidade' (Borba, 2013) e perfeita sala de aula ao ar livre para as geociências, município que conta com todos os principais tipos de rochas e estruturas geológicas, além da beleza das Pedras das Guaritas (PAIM et al., 2010) e da Serra do Segredo (Fig. 2B, BORBA et al., 2011).

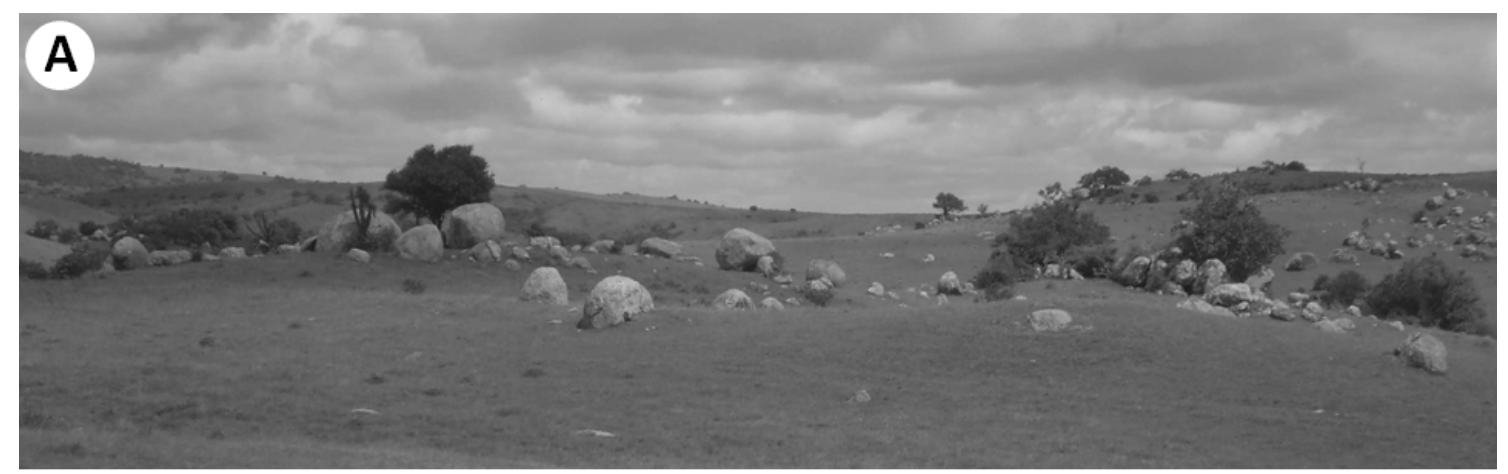

\section{B}

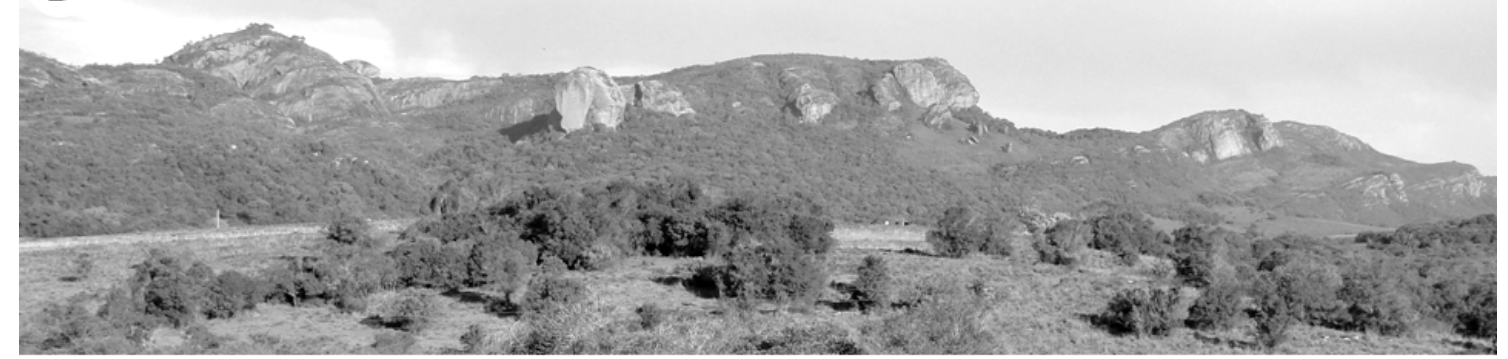

Figura 2 - Destaques geopatrimoniais do Escudo Sul-rio-grandense: (A) paisagem de campos de matacões arredondados de granitos na zona rural do município de Herval; (B) paisagem da Serra do Segredo, desenvolvida sobre conglomerados fluviais do Paleozoico inferior, em Caçapava do Sul. 
Ainda mais a oeste, estão as unidades geomorfológicas Depressão Periférica e Cuesta do Haedo, cujo substrato é composto pelas rochas sedimentares e vulcânicas da Bacia do Paraná, do Paleozoico e Mesozoico. Na Depressão Periférica, em municípios como Rosário do Sul e São Gabriel, destacam-se os morros-testemunho e cerros tabulares (Fig. 3A) da Serra do Caverá e das coxilhas do Batovi ('seio de moça', na língua nativa dos charruas, antiga tribo pampeana). Os areais da campanha (Fig. 3B), especialmente no município de Alegrete, constituem remanescentes de um tipo de paisagem que já dominou o pampa gaúcho durante o último máximo glacial (18 mil anos antes do presente), e por isso podem ser considerados patrimônio geológico (uma geomemória) do Rio Grande do Sul. Por fim, na Cuesta do Haedo (ou região do Arapey), a principal feição é o Cerro do Jarau (Fig. 3C), uma feição circular interpretada como cratera de meteoro (e.g. Phillip et al., 2010). Esse cerro é o palco de uma das principais lendas da tradição gaúcha, a lenda da 'Salamanca do Jarau' (Simões Lopes Neto, 1913, 2002).
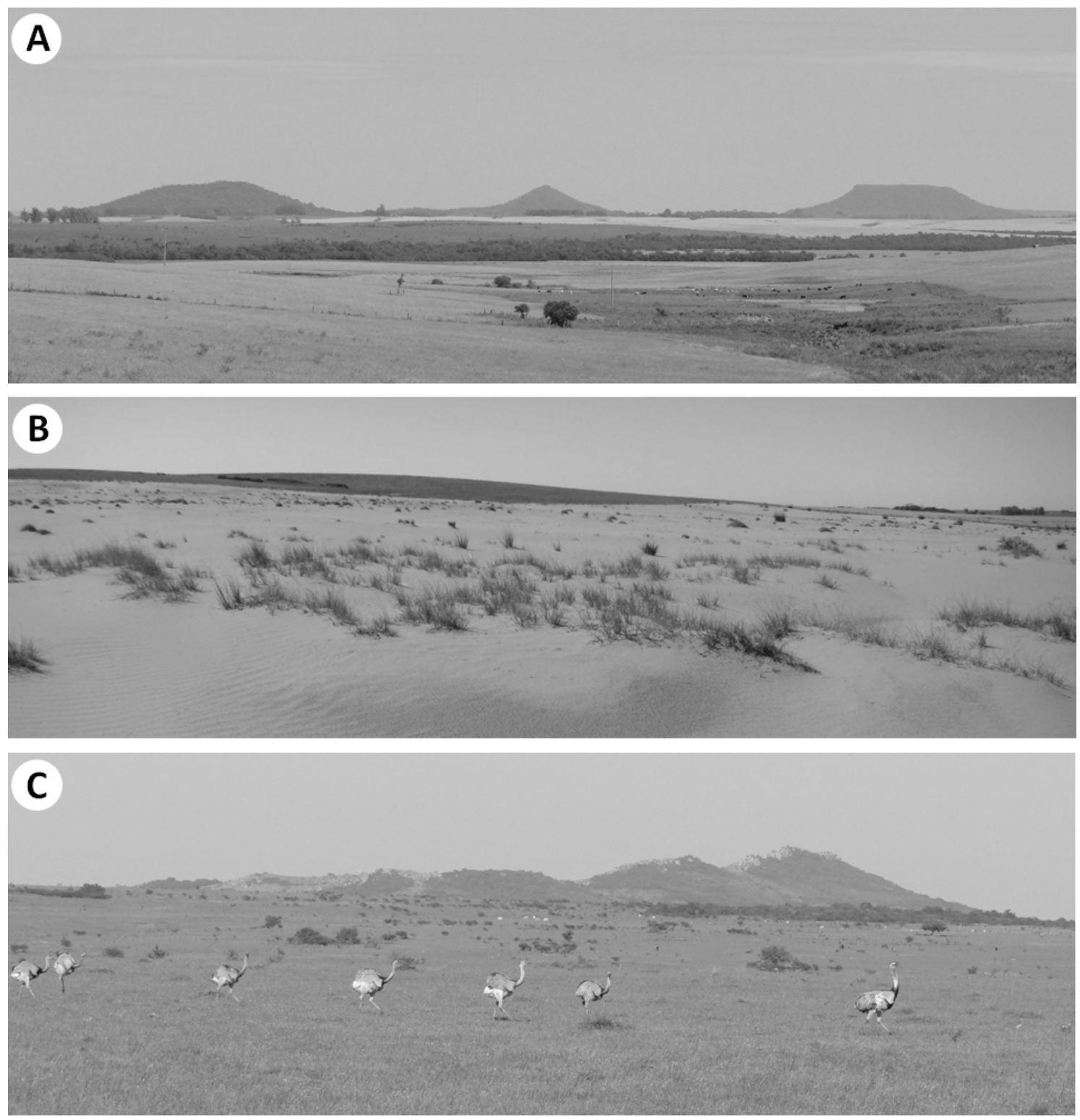

Figura 3 - Destaques geopatrimoniais da Depressão Periférica e da Cuesta do Haedo: (A) paisagem na região de São Vicente do Sul, a oeste de Santa Maria, com cerros tabulares e pequenos cerros agudos, mas suaves, a que os charruas chamavam batovi ('seio de moça'); (B) panorama de um areal da campanha gaúcha, em Alegrete, remanescente de épocas mais secas e mais frias no oeste do RS; (C) porção oeste do Cerro do Jarau, estrutura circular interpretada como cratera de impacto de meteoro; em primeiro plano, um grupo de emas (Rhea americana), aves típicas do pampa gaúcho. 


\section{REALIDADE REGIONAL E IMPLICAÇÕES PARA A GEOCONSERVAÇÃO, O GEOTURISMO E OS GEOPARQUES}

A realidade atual da 'metade sul' gaúcha impõe uma série de oportunidades e dificuldades para a implantação de projetos ou estratégias de geoconservação. Em primeiro lugar, a densidade demográfica é muito baixa: a 'metade sul' do Rio Grande do Sul continua a ser 'o país da solidão' (Barbosa Lessa, 1985). Se esse fator permitiu uma efetiva preservação do meio ambiente e das belezas naturais (muito mais pelo isolamento do que por um real cuidado), implica dificuldades de infraestrutura. Aglomerados urbanos significativos existem apenas junto ao litoral: as cidades de Pelotas e Rio Grande que, juntas, chegam a 500 mil habitantes. No restante do território, a realidade é de municípios extensos, rurais, de vocação pecuarista, com zonas urbanas pequenas e tipicamente com menos de 40 mil habitantes. As distâncias são grandes: cem quilômetros entre Caçapava do Sul e São Gabriel, e mais cento e vinte quilômetros entre Rosário do Sul e Alegrete. As rodovias asfaltadas são poucas, em comparação com uma extensa malha de estradas vicinais, de 'chão batido', por vezes pedregosas ou em mau estado de conservação, cruzando sangas através de pontilhões precários cuja segurança é muitas vezes questionada (com razão) durante visitas a campo. Hotéis e restaurantes são aceitáveis apenas para um público menos exigente, não apresentando um nível turisticamente interessante. Os públicos que utilizam tais estabelecimentos, hoje, são formados por representantes de laboratórios de produtos veterinários e agrícolas, além de estudantes das ciências naturais, em saída de campo (ou seja, a trabalho).

A 'metade sul' é a região menos desenvolvida do Rio Grande do Sul, tanto em termos humanos quanto econômicos, como revelam levantamentos do índice IDH (bloco educação) e do PIB per capita. A escola, no pampa, é caracterizada por alta evasão, atrasos na seriação e desempenho fraco em exames nacionais (IDEB, ENEM); crianças cujos pais estudaram pouco, e que começam a trabalhar cedo nas lidas do campo ou nas oficinas das cidades. Sem instrução, sem qualificação, sem emprego, o jovem da 'metade sul' ainda segue a tendência do êxodo rural (a 'ilusão povoeira' da canção nativista) e vai engrossar as periferias de Porto Alegre, Canoas, Caxias do Sul ou Novo Hamburgo. Sem potencial para a agricultura de precisão e para as grandes safras de soja, a 'metade sul' não é valorizada nem mesmo dentro do Rio Grande do Sul. Atrasada e, até certo ponto, abandonada até pelos representantes, a região tornou-se vulnerável frente a setores econômicos agressivos, como a mineração e a silvicultura para a indústria da celulose e papel.

As características regionais mencionadas (infraestrutura deficiente, fracos resultados humanos e socioeconômicos, e vulnerabilidade frente a setores agressivos) fazem com que iniciativas de geoconservação na 'metade sul' sejam urgentes e devam ser planejadas e executadas com a maior brevidade possível. No entanto, é necessário fazer um alerta: com o atual panorama, deve-se pensar em iniciativas baratas, baseadas na doação (de recursos, de esforços, de conhecimento) e na gratuidade, que busquem a solução dos problemas existentes. Neste momento, em que faltam estrutura, educação básica e condições dignas às comunidades, não cabem sonhos imediatistas de 'geoparques' apenas pela certificação, na busca de um reconhecimento internacional para algo que não existe. O que de fato existe é apenas o singular geopatrimônio e o enorme potencial da região. Dessa forma, o momento em que os inventários geopatrimoniais se completam é apenas o momento em que deve começar o trabalho fundamental de geoconservação: (1) proteção legal e física de geossítios importantes ou ameaçados; (2) projetos de educação ambiental/geopatrimonial, com a necessária participação gratuita das universidades e dos pesquisadores; (3) incentivo ao estabelecimento de roteiros geoturísticos, inserção de informações geológicas em locais já visitados, etc.

Ainda no campo do geoturismo, é necessário considerar o fato de que o Rio Grande do Sul (assim como grande parte do Brasil) não possui um contingente substancial de turistas interessados em geologia e natureza, e que também é necessário um trabalho básico de informação e conscientização à sociedade. Um público que pode ser imediatamente atingido pelo geoturismo nessa região é o dos praticantes de esportes de aventura na natureza, que já frequentam alguns locais específicos, como áreas de escalada em rocha em Caçapava do Sul. Um ponto positivo é a existência de alguns fluxos turísticos já bem estabelecidos e que cortam a região. O primeiro é o fluxo de pessoas de Porto Alegre, Santa Maria e outras regiões desenvolvidas do Estado em direção à fronteira com o Uruguai, para realizarem compras nos free-shops da cidade de Rivera. Tais consumidores utilizam as rodovias federais BR-290, BR-153 e BR-158, todas com muitas paisagens de substancial significado geológico. No entanto, ao trafegarem em rodovias desprovidas de uma estrutura de miradores com painéis interpretativos, não aproveitam o passeio para 
adquirirem mais conhecimento. Outra peculiaridade da região reside no fato de que, anualmente, milhares de turistas da região do Prata (uruguaios e argentinos) cruzam a 'metade sul' gaúcha nos meses de verão, basicamente nas mesmas rodovias citadas. Este público também pode ser conquistado e convidado a permanecer mais um ou dois dias, antes de seguir ao litoral catarinense. Por esse motivo, recomenda-se que as estratégias de divulgação do potencial geoturístico e da informação geocientífica, especificamente na 'metade sul' gaúcha, devam ser oferecidas sempre em português e espanhol.

\section{CONSIDERAÇÕES FINAIS}

Neste trabalho, buscou-se analisar e apresentar as características da 'metade sul' gaúcha, tanto em termos do seu patrimônio geológico singular quanto da precariedade de sua infraestrutura e de seus indicadores humanos e socioeconômicos. Analisaram-se, também, alguns fluxos turísticos já existentes, que poderão fornecer potenciais geoturistas ou, pelo menos, turistas um pouco mais informados sobre a natureza regional. Todas as características apresentadas trazem implicações para os modelos a serem utilizados para a geoconservação na 'metade sul' do Rio Grande do Sul: (a) proteção de geossítios e paisagens singulares, (b) iniciativas de baixo custo, (c) foco prioritário na educação geopatrimonial, (d) investimento na sinalização em rodovias onde já haja um fluxo turístico (mesmo que não geoturístico) bem estabelecido. Salientou-se, ainda, que as iniciativas listadas acima devem ser projetadas, executadas, avaliadas e monitoradas muito antes de qualquer ilusão sobre certificações do tipo 'geoparque'.

\section{REFERÊNCIAS BIBLIOGRÁFICAS}

Barbosa Lessa L.C. 1985. Rio Grande do Sul, prazer em conhecê-lo. Editora Globo, Porto Alegre, 2a Edição.

Borba A.W. 2013. Geoconservação em Caçapava do Sul (Escudo Sul-rio-grandense, RS, Brasil): ideias e sugestões com base em avaliação geopatrimonial. In: VIII Simpósio Sul-brasileiro de Geologia, Resumos, Porto Alegre.

Borba A.W., Souza L.F., Porto P.R., Petry A.C. 2011. A paisagem da Serra do Segredo (Caçapava do Sul, RS) como patrimônio geológico brasileiro: características, riscos à integridade e estratégias de conservação. In: I Simpósio Brasileiro de Patrimônio Geológico, Rio de Janeiro, Atas, p. 9.

Chemale Jr. F. 2000. Evolução geológica do Escudo Sul-riograndense. In: Holz M. \& De Ros L.F. (eds.) Geologia do Rio Grande do Sul, Edições CIGO/UFRGS, pp. 13-52.

Lopes R.P., Ugri A., Buchmann F.S.C. 2008. Dunas do Albardão, RS: bela paisagem eólica no extremo sul da costa brasileira. In: SIGEP Sítios Geológicos e Paleobiológicos do Brasil, Sítio 003. Disponível em http://sigep.cprm.gov.br/sitio003/sitio003_impresso.pdf, p. 131-140, acesso em 10/8/2013.

Lopes R.P., Buchmann F.S.C., Caron F., Itusarry M.E.G.S. 2005. Barrancas fossilíferas do Arroio Chuí, RS: importante megafauna pleistocênica no extremo sul do Brasil. In: SIGEP Sítios Geológicos e Paleobiológicos do Brasil, Sítio 119. Disponível em http://sigep.cprm.gov.br/sitio119/sitio119.pdf, acesso em 10/8/2013.

Paim P.S.G., Fallgater C., Silveira A.S. 2010. Guaritas do Camaquã, RS: exuberante cenário com formações geológicas de grande interesse didático e turístico. In: SIGEP Sítios geológicos e paleontológicos do Brasil, Sítio 076. Disponível em www.unb.br/ig/sigep/sitio076/sitio076.pdf, acesso em 10/8/2013.

Phillip R.P., Rolim S.B.A., Sommer C.A., Souza Filho C.R., Lisbôa, N.A. 2010. A estrutura de impacto do Cerro do Jarau, Quaraí, RS. Revista Brasileira de Geociências, 40(4): 468-483.

Simões Lopes Neto, J. 2002. Lendas do Sul. Porto Alegre, Artes e Ofícios, 159p. (original de 1913).

Contribuição ao II Simpósio Brasileiro de Patrimônio Geológico

I Workshop Brasileiro de Patrimônio Geológico Construído 